\title{
Measuring decadal vertical land-level changes from SRTM-C (2000) and TanDEM-X ( 2015) in the south-central Andes
}

\author{
Benjamin Purinton and Bodo Bookhagen \\ Institute of Earth and Environmental Science, Universität Potsdam, Potsdam, Germany \\ Correspondence: Ben Purinton (purinton@uni-potsdam.de)
}

Received: 20 June 2018 - Discussion started: 6 July 2018

Revised: 17 September 2018 - Accepted: 22 October 2018 - Published: 30 October 2018

\begin{abstract}
In the arctic and high mountains it is common to measure vertical changes of ice sheets and glaciers via digital elevation model (DEM) differencing. This requires the signal of change to outweigh the noise associated with the datasets. Excluding large landslides, on the ice-free earth the land-level change is smaller in vertical magnitude and thus requires more accurate DEMs for differencing and identification of change. Previously, this has required meter to submeter data at small spatial scales. Following careful corrections, we are able to measure land-level changes in gravel-bed channels and steep hillslopes in the south-central Andes using the SRTM-C (collected in 2000) and the TanDEM-X (collected from 2010 to 2015) near-global 12-30 m DEMs. Long-standing errors in the SRTM-C are corrected using the TanDEM-X as a control surface and applying cosine-fit co-registration to remove $\sim 1 / 10$ pixel $(\sim 3 \mathrm{~m})$ shifts, fast Fourier transform (FFT) and filtering to remove SRTM-C short- and long-wavelength stripes, and blocked shifting to remove remaining complex biases. The datasets are then differenced and outlier pixels are identified as a potential signal for the case of gravel-bed channels and hillslopes. We are able to identify signals of incision and aggradation (with magnitudes down to $\sim 3 \mathrm{~m}$ in the best case) in two $>100 \mathrm{~km}$ river reaches, with increased geomorphic activity downstream of knickpoints. Anthropogenic gravel excavation and piling is prominently measured, with magnitudes exceeding $\pm 5 \mathrm{~m}$ (up to $>10 \mathrm{~m}$ for large piles). These values correspond to conservative average rates of 0.2 to $>0.5 \mathrm{~m} \mathrm{yr}^{-1}$ for vertical changes in gravel-bed rivers. For hillslopes, since we require stricter cutoffs for noise, we are only able to identify one major landslide in the study area with a deposit volume of $16 \pm 0.15 \times 10^{6} \mathrm{~m}^{3}$. Additional signals of change can be garnered from TanDEM-X auxiliary layers; however, these are more difficult to quantify. The methods presented can be extended to any region of the world with SRTM-C and TanDEM-X coverage where vertical land-level changes are of interest, with the caveat that remaining vertical uncertainties in primarily the SRTM-C limit detection in steep and complex topography.
\end{abstract}

Geodynamic and geomorphological processes operating at different timescales result in vertical change (herein $d h$ ) on the earth's surface. In the cryosphere, $d h$ studies use repeat surveys or digital elevation model (DEM) differencing on annual to sub-annual time steps (e.g., Berthier et al., 2007; Nuimura et al., 2012; Neelmeijer et al., 2017; Brun et al., 2017). Changes to snow and ice occur most rapidly (aside from landslides), but $d h$ measurement outside of the cryosphere also provide aggradation and incision monitoring for rivers (e.g., Lane et al., 2003; Wheaton et al., 2010; Cook, 2017; Mason and Mohrig, 2018), volumes of landslides and extruded lava (e.g., Bagnardi et al., 2016; Bessette-Kirton et al., 2018), and earthquake displacements (Oskin et al., 2012). Large-scale monitoring of $d h$ on soil, rock, and unconsolidated sediment is an elusive problem requiring signals that outweigh the noise in collection methods and resulting datasets. 
Vertical accuracies for modern gridded spaceborne DEMs are on the order of $2-8 \mathrm{~m}$ in mountainous regions, though significantly worse on steepening slopes (e.g., Rexer and Hirt, 2014; Purinton and Bookhagen, 2017). Using DEMs from sources like the Advanced Spaceborne Thermal Emission and Reflection Radiometer (ASTER; Tachikawa et al., 2011) with higher uncertainties is acceptable for monitoring glaciers and ice sheets (e.g., Brun et al., 2017), where $d h$ between even sub-annual time steps can be tens to hundreds of meters over areas of many square kilometers. On the other hand, $d h$ of soil, rock, and unconsolidated sediment are often at the centimeter to meter scale and far more localized over up to a few hundred to thousand square meters. Due to these limitations, previous studies relied on intensive mapping from aerial photos (e.g., Hovius et al., 1997), sparse cross sections with large temporal spans (e.g., Rinaldi and Simon, 1998), or - more recently - meter to submeter topographic data from lidar or photogrammetric point clouds (e.g., Lane et al., 2003; Booth et al., 2009; Perroy et al., 2010; Cook, 2017) or select optical satellites with submeter resolution like Pleiades and WorldView (e.g., Bagnardi et al., 2016; Bessette-Kirton et al., 2018). Despite recent advances in meter to submeter lidar, satellite, and unmanned aerial vehicle data availability (Passalacqua et al., 2015), these remain limited in spatial and temporal coverage, and sometimes prohibitively expensive. Coarser gridded DEMs from radar and optical spaceborne sensors remain the best and often the only option in large or remote areas.

The publicly available Shuttle Radar Topography Mission (SRTM) DEM is an earth snapshot from its 10-day collection aboard the Space Shuttle Endeavour in February 2000. The mission produced an interferometric synthetic aperture radar (InSAR) DEM from C-band $(5.6 \mathrm{~cm}$ wavelength) radar for $80 \%$ of earth's landmasses from typically 2-3 ascending and descending swaths (Farr et al., 2007). The SRTM-C has seen numerous succeeding releases and void filling (e.g., Jarvis et al., 2008). We use the most recent floating-point-reprocessed $1 \operatorname{arcsec}(\sim 30 \mathrm{~m})$ NASADEM, taking only the non-void-filled original SRTMC tiles (herein SRTM-C; Crippen et al., 2016; found in the "srtmOnly" directories under https://e4ftl01.cr.usgs.gov/ provisional/MEaSUREs/NASADEM/, last access: 26 October 2018).

The TanDEM-X 0.4 and $1 \operatorname{arcsec}(\sim 12$ and $\sim 30 \mathrm{~m})$ DEM released in 2016 - here received through scientific German Aerospace Center (DLR) proposals - is the next generation of radar-derived global topography following the SRTM. The TanDEM-X, covering $97 \%$ of earth's landmasses, was generated by semi-automated processing and stacking of $>470000$ ascending and descending $X$-band $(3.1 \mathrm{~cm}$ wavelength) TerraSAR-X and TanDEM-X satellite bistatic scenes collected from December 2010 to January 2015 (Krieger et al., 2013; Rizzoli et al., 2017). As elevations are averaged between scenes, we take the date of the TanDEM-X as January 2015, thus providing a 15-year time step of $d h$ between
SRTM-C and TanDEM-X. Using the latest possible date for TanDEM-X elevations means that rates of change are conservative minimum values.

In this submission we discuss the errors associated with each of these datasets and the corrections applied to mitigate uncertainties in their differencing for $d h$ detection outside of the cryosphere. This is therefore a data quality and methods-focused study. Geomorphic change detection is applied via correction and differencing of the TanDEM-X and SRTM-C over the south-central Andes in northwestern Argentina (Fig. 1) to identify and measure areas of $d h$ in gravel-bed channels specifically and then across the landscape. Here, steep gradients in elevation $(\sim 1-4 \mathrm{~km})$, rainfall $\left(\sim 0.1-1 \mathrm{~m} \mathrm{yr}^{-1}\right)$, and vegetation (subtropical forests and croplands to arid, succulent-covered slopes) cause high rates of mass transfer (Bookhagen and Strecker, 2012; Savi et al., 2016; Schildgen et al., 2016), further influenced by climate change (Castino et al., 2016a, b, 2017) and anthropogenic modification (gravel mining and weirs). To conclude, we discuss caveats driven by remaining uncertainties prevalent in spaceborne DEMs collected over complex topography.

\section{Spaceborne DEM errors}

Yamazaki et al. (2017) classify spaceborne DEM errors into speckle noise, stripe noise, absolute bias, and tree height bias. We divide this further for the case of SRTM-C and TanDEM-X (both radar DEMs) into (i) sensor specific related to radar and spacecraft collection and (ii) terrain specific related to land-surface cover and topographic complexity. We do not consider DEMs from optical sensors such as ASTER (Tachikawa et al., 2011) and the Advanced Land Observing Satellite (ALOS; Tadono et al., 2014), which have well documented errors (e.g., Racoviteanu et al., 2007; Nuth and Kääb, 2011; Fisher et al., 2013; Yamazaki et al., 2017) and perform worse than radar, with vertical accuracies $>5 \mathrm{~m}(1 \sigma)$ and persistent high-frequency artifacts (Purinton and Bookhagen, 2017). Additionally, a dearth of cloud-free, high-quality ASTER imagery covering the study area precludes the automated DEM generation of Girod et al. (2017) and regression techniques of Wang and Kääb (2015). On the other hand, within the study area, the SRTM-C and TanDEM$\mathrm{X}$ both exhibit vertical uncertainties $<3.5 \mathrm{~m}$ (Purinton and Bookhagen, 2017) and also have an appropriately long time difference for vertical land-level change detection. Auxiliary rasters including the water indication mask (WAM), height error mask (HEM), consistency mask (COM), and coverage map (COV) delivered with TanDEM-X (Wessel, 2018) allow enhanced understanding of DEM quality (see Sect. S1 in the Supplement).

Random, or speckle, error caused by instrument thermal noise and localized de-correlation is the primary sensor bias for radar (Rodríguez et al., 2006). These localized, small magnitude errors reduce with increasing looks used in the 

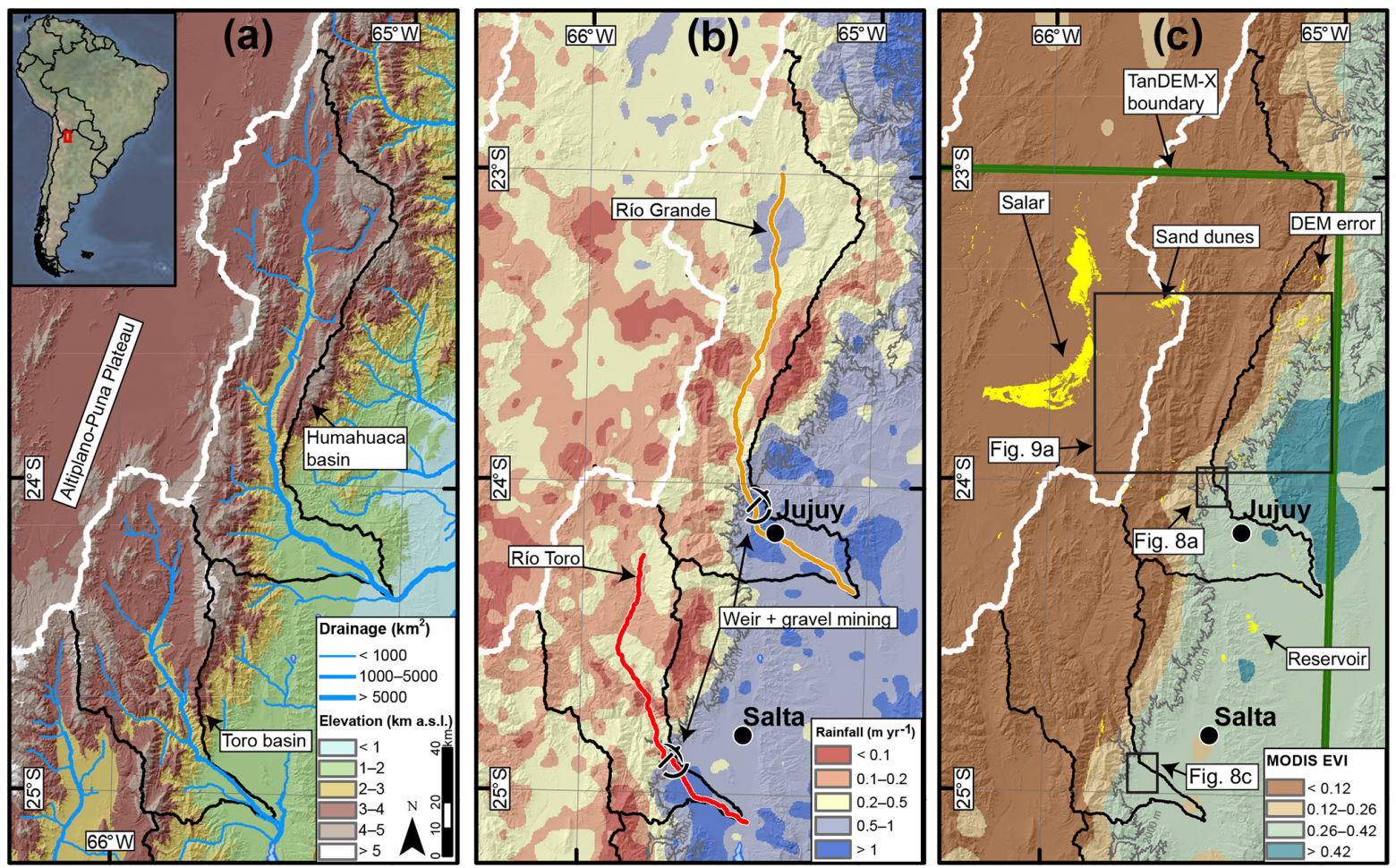

Figure 1. Overview of study area in NW Argentina with (a) elevation, (b) rainfall (Tropical Rainfall Measurement Mission 12-year average; TRMM2B31; Bookhagen and Strecker, 2008), and (c) vegetation (MODIS product 13C1 enhanced vegetation index 14-year average; MODIS EVI; Huete et al., 1994), where lower, brown (higher, green) values represent sparse (dense) vegetation. Note strong east-west gradients in all three maps. The white watershed boundary delineates the internally drained Altiplano-Puna Plateau. The gray line in (b) and (c) indicates the $2000 \mathrm{~m}$ contour line. The yellow patches in (c) are areas identified in the TanDEM-X water indication mask (WAM) as having low amplitude and/or low coherence. These patches correspond to salt flat (salar) regions on the plateau, water bodies (e.g., reservoirs in the low-elevation areas), steep and vegetated areas (DEM error), and other zones of coherence loss, such as the dunes identified. Inset boxes in (c) indicate locations of $d h$ map-view Figs. 8-9, with the TanDEM-X tile boundary in green. Note anthropogenic tampering of natural gravel-bed channels (Río Grande and Río Toro) with downstream flow diversion (weirs) and gravel mining activity near the populous cities of Salta and Jujuy.

final mosaic. Speckle presents a greater issue in SRTM-C given the maximum three swaths at lower latitudes (Farr et al., 2007). Such noise is expected to be minimal in the TanDEM-X, with average coverage in our study area of 7 ascending and descending scenes and up to 14 in many steep areas (Fig. S1 in the Supplement). Smoothing data prior to and after phase unwrapping (e.g., multi-looking, adaptive filters, or down-sampling) can further reduce speckle. The SRTM$\mathrm{C}$ raw resolution of $\sim 30 \mathrm{~m}$ is similar to the final $1 \mathrm{arcsec}$ product, though, due to interferogram smoothing to reduce noise, the estimated true ground resolution of the final product is 45-60 m (Sun et al., 2003; Farr et al., 2007; Tachikawa et al., 2011). This may be improved in the newly released data (Crippen et al., 2016), but this remains to be tested. Multi-looking of $4 \times 5$ pixels of raw radar returns (resolution $\sim 3.3 \mathrm{~m}$ ) was used in the case of TanDEM-X to generate a final $0.4 \operatorname{arcsec}(\sim 12 \mathrm{~m})$ product, thus significantly smoothing and reducing speckle (Rizzoli et al., 2017).
Besides a small geolocation error expected in both DEMs from instrument uncertainties, the SRTM-C has a number of spacecraft-specific biases, manifested in short- and longwavelength striping (Rodríguez et al., 2006; Yamazaki et al., 2017). The short-wavelength $(\sim 0.5-1 \mathrm{~km}$, magnitudes typically $<0.5 \mathrm{~m}$ ) stripes are related to jitter in the antenna mast caused by the periodic firing of shuttle attitude thrusters (Farr et al., 2007). Longer-wavelength errors with magnitudes $>1 \mathrm{~m}$ are caused by individual swath tilts and form complex undulating patterns over $\sim 100 \mathrm{~km}$ distances (Crippen et al., 2016; Yamazaki et al., 2017). TanDEM-X satellite biases can be found in slight tilting of individual TerraSAR$X$ and TanDEM-X scenes (e.g., Neelmeijer et al., 2017), though these tilts were removed during stacking in the end product (Rizzoli et al., 2017). The careful monitoring and control maintained over flight geometry, in addition to postprocessing to remove tilts using ICESat (Ice, Cloud, and land Elevation Satellite; Schutz et al., 2005), restricts most of the 
TanDEM-X uncertainty to the second category of terrainspecific error (Rizzoli et al., 2017).

Land-surface cover plays a key role in modulating radar returns. TanDEM X-band and SRTM C-band radar have different penetration depths in dense vegetation (Carabajal and Harding, 2006; Hofton et al., 2006; Wessel et al., 2018) and snow and ice (Rignot et al., 2001; Rossi et al., 2016), leading to different height returns. We note this important caveat but are able to ignore it for our particular study question (landlevel change of bare material) and area (only partial vegetation and no permanent snow and ice). Subtropical vegetation in our study area does allow some exploration of the effect on $d h$; however, we find no clear relation (see Sect. S2). In any case, vegetation differences are expected to be less significant than for optical data, which returns only the canopy heights (e.g., Yamazaki et al., 2017). Both DEMs have major inconsistencies and speckle over water bodies, wet salt flats, and deserts caused by de-correlation, variable reflectance, and/or weak backscatter of the radar signal (Rodríguez et al., 2006; Farr et al., 2007; Wendleder et al., 2013; Rizzoli et al., 2017). For the SRTM-C, these areas are largely voids anyway, and for TanDEM-X the WAM raster provides information on coherence and amplitude for each pixel to identify these untrustworthy measurements (Fig. 1c).

Remaining errors in the SRTM-C and TanDEM-X are related to terrain characteristics (see Sect. S2). This is the result of topographic complexity below the resolution of the sensor, radar geometry considerations (layover, foreshortening, and shadowing), and interferometric phase unwrapping errors, all most pronounced in steep mountains. Such terrain biases are demonstrated in the SRTM-C with elevation (Berthier et al., 2006; Paul, 2008), slope and aspect (Gorokhovich and Voustianiouk, 2006; Van Niel et al., 2008; Peduzzi et al., 2010; Shortridge and Messina, 2011), and resolution (manifested in curvature) (Gardelle et al., 2012), and in the TanDEM$\mathrm{X}$ with only slope (Purinton and Bookhagen, 2017; Wessel et al., 2018). Terrain slope - also related to relief (Fig. S7) - is the primary cause of error in any DEM, demonstrated in the division of vertical uncertainties for most DEMs into slope bins (e.g., Wessel et al., 2018). Slope-dependent errors may be reduced with finer-resolution data and increased look angles for mosaicking, as in the case of TanDEM-X, but these uncertainties are expected to remain as the most prevalent cause of error in any spaceborne DEM.

With this framework for understanding the potential error sources in the SRTM-C and TanDEM-X, it is possible to correct one dataset to another in a multistep processing chain (e.g., Yamazaki et al., 2017) allowing $d h$ identification and measurement with greater certainty.

\section{Methods}

Given the excellent agreement with differential GPS globally (Wessel et al., 2018) and in the study area (Purinton and Bookhagen, 2017) along with the minimal errors associated with orbital characteristics, we consider the TanDEM-X DEM as our reference surface in order to correct the more problematic SRTM-C. During correction, we do not apply any speckle reduction (e.g., via an adaptive filter as in Yamazaki et al., 2017), as we are interested in raw elevation values and not a smoothed DEM. For the SRTM-C we select the non-void-filled NASADEM data so as not to include any auxiliary elevation measurements from, for instance, ASTER (Crippen et al., 2016). Importantly, both DEMs are referenced to the WGS84 ellipsoid vertical datum, whereas previous SRTM-C releases have been referenced to the EGM96 geoid (Farr et al., 2007), thus requiring a geoid-adjustment step introducing additional uncertainties prior to comparison.

For correction and differencing we use the $0.4 \operatorname{arcsec}$ TanDEM-X that we bilinearly resampled to 1 arcsec to match the raw resolution of the SRTM-C. Wessel (2018) notes that the delivered TanDEM-X 1 arcsec tiles, which we also have a number of, were generated with average resampling of the 0.4 arcsec tiles by DLR and not by any increase in multilooks or interferogram smoothing. We tested a number of resampling schemes including average, bilinear, cubic, and cubic spline on the original 0.4 arcsec tiles and found better results (lower vertical uncertainty compared with differential GPS) from the commonly used bilinear resampling, whereas the unedited 1 arcsec tiles delivered by the DLR - generated by average resampling - had higher vertical uncertainties.

The TanDEM-X and recently updated SRTM-C were both referenced to high-accuracy ICESat (Schutz et al., 2005; Zwally et al., 2009) measurements (collected between 2003 and 2009) during final block adjustments (Crippen et al., 2016; Rizzoli et al., 2017). While this removes the complete independence of these datasets, the relative sparsity of these points ( $170 \mathrm{~m}$ along track and up to $80 \mathrm{~km}$ across track) does not provide a continuous adjustment surface, but rather acts to improve local elevations and overall DEM quality with respect to remaining tilts (Rizzoli et al., 2017). Throughout the study $d h$ refers to the TanDEM-X-SRTM-C 15-year differences (including both real change and vertical uncertainties).

\subsection{SRTM-C correction steps}

Our correction chain was applied using the previous SRTM$\mathrm{C}$ output at each stage as input in the following step. All steps were carried out on a $1^{\circ} \times 1^{\circ}$ tile-by-tile basis (unprojected WGS84 vertical and horizontal datums); however, merging tiles and then processing produced identical results. We also found comparable results using Universal Transverse Mercator (UTM) equal area projected tiles. The correction steps served to correct SRTM-C orbital biases and did not attempt to correct for terrain characteristics. We assumed that actual vertical change in our study area represented an extremely small fraction of pixels in the $\sim 13$ million pixel $d h$ raster for each tile. This ensures that the corrections only rectified SRTM-C biases on stable terrain and were 
not influenced by smaller areas of true vertical land-level changes. Comparison of correction steps was done using normalized percentage difference histograms and quantilequantile (QQ) plots.

\subsubsection{Co-registration}

We corrected for subpixel offsets known to affect DEM comparisons (Van Niel et al., 2008; Berthier et al., 2007) using the universal co-registration of Nuth and Kääb (2011). This rigid translation is based on a cosine function fit to the relationship between terrain aspect and $d h$ normalized by terrain slope:

$$
\frac{d h}{\tan (\alpha)}=a \cdot \cos (b-\psi)+c,
$$

where $\alpha$ is slope; $\psi$ is aspect; and the variables $a, b$, and $c$ are the magnitude, direction, and mean bias, respectively. The shifts were applied to the SRTM-C by bilinear resampling with the $d x=a \cdot \cos (b)$ and $d y=a \cdot \sin (b)$ vectors used to weight the neighboring cells, and the mean shift $d z=c \cdot \tan (\bar{\alpha})$ was added at the end.

We fit Eq. (1) to only slopes $>5^{\circ}$ and, if necessary based on goodness-of-fit parameters, continued iteration of the fitting, shift vector solving, and interpolation until the magnitude of the shift vector $(\boldsymbol{a})$ was $<0.5 \mathrm{~m}$ or the reduction in normalized median absolute difference (NMAD; Höhle and Höhle, 2009) on stable terrain was $<5 \%$ (Nuth and Kääb, 2011).

Our co-registration did not correct for slope and curvature using polynomial fitting (e.g., Kääb, 2005; Gardelle et al., 2012) as this introduces empirical models and additional uncertainties. We did not observe a linear positive or negative trend between slope and $d h$ (Fig. S7). Curvature versus $d h$ demonstrates the difference in actual resolution of raw sensor data between the SRTM-C and TanDEM-X (Fig. S10); however, correction of this intrinsic measurement limit introduces artificial elevations and is thus inappropriate for $d h$ mapping between DEMs from different data sources and time steps (see Sect. S2).

Iterative shifting and bilinear resampling of one DEM to another by decimeter steps had the same effect on rectifying aspect biases (same shift vectors leading to minimization of bias) as the empirical fitting of the cosine relationship and calculation of shift vectors (see Iterative Shifting Video in the Supplement). This indicates the robust nature of the method of Nuth and Kääb (2011), assuming a sufficient distribution of high-slope, multi-aspect-facing topography is available for cosine fitting. The minimization of the sum of errors and cross-correlation methods (e.g., Kääb, 2005) were unsuccessful at removing shifts in our study region.

\subsubsection{Destriping}

For removal of long- and short-wavelength striping patterns in the SRTM-C, we followed previous work using frequency analysis techniques to identify striping artifacts (e.g., Arrell et al., 2008) and noise (e.g., Purinton and Bookhagen, 2017) in DEMs. We took particular inspiration from Yamazaki et al. (2017) and used fast Fourier transforms (FFTs) to filter the $d h$. In a first step, we removed all pixels identified as having low coherence in the TanDEM-X WAM. This filtered large water bodies and other areas that may show artifact noise affecting FFT analysis. Following this, any void pixels (including the low-coherence areas) were set to $d h=0$ and an FFT was run. The power spectral density (PSD) was calculated as the magnitude of the FFT squared and a mean $5 \times 5$ filter was passed over it. The ratio of original and smoothed PSD was then taken to identify regions of the spectrum with high outliers (high ratio) representing cyclic, tilespanning stripe bias. We used the 97.5th percentile of the ratio as the cutoff value. The remaining top $2.5 \%$ high- and low-frequency outliers received an inverse FFT, which produced a map of the long- and short-wavelength stripes. These stripes were then removed from the SRTM-C and the process was repeated iteratively until the improvement in root mean squared error (RMSE) was $<5 \%$.

We refer to the above parameters as nonaggressive destriping, since we are just "shaving off" the top of the distribution. In aggressive tests, we experimented with lower percentile cutoff values (e.g., 95th) and lower tolerance for RMSE convergence (e.g., $<2 \%$ improvement). While these more aggressive destriping schemes did successfully eliminate the SRTM-C orbital biases, we also found that the true topography was often filtered following the more than five iterations needed to meet the RMSE convergence requirements (Fig. S11). Therefore, we chose to use the nonaggressive cutoffs and ran additional blocked shifting discussed in the following section.

\subsubsection{Blocked shifting}

Patchy positive and negative regions in the co-registered, destriped $d h$ map were solved by breaking the $1^{\circ} \times 1^{\circ}$ tile into square blocks and shifting each block by the median value. These areas likely correspond to remaining orbital biases that were not removed in our nonaggressive destriping technique. There may be local correspondence between these patches and atmospheric water vapor conditions at the time of SRTM-C collection in February 2000; however, such data at the sub-kilometer scale necessary for analysis is unavailable. Furthermore, local adjustment of the SRTM-C and TanDEM-X to ICESat measurements could contribute to these shifts, though the contribution is difficult to quantify.

We began by masking the low-coherence pixels (again from the WAM) since these would disproportionately contribute to local median shifts. Using a variety of block sizes 
with edge lengths ranging from 1.35 to $7.2 \mathrm{~km}$, we found the median $d h$ and median slope in each block. We used the median slope to normalize the median $d h$ values, since we expect areas of higher slope to have greater uncertainties and biases (Fig. S7) unrelated to SRTM-C orbital biases. Furthermore, we allowed a maximum shift per block of $\pm 1 \mathrm{~m}$, thus ensuring that this step did not cause unreasonably large shifts due to outliers contained in a given block.

\subsection{Differencing for change detection}

Following orbital SRTM-C bias corrections, it is possible to merge corrected tiles and create maps of $d h$ to measure areas of actual change. Previous change mapping over gravel-bed channels has relied on level-of-detection cutoffs and probabilistic thresholding (e.g., Lane et al., 2003; Wheaton et al., 2010). These studies have, however, been developed for meter to submeter photogrammetric or lidar data. Here we use a hybrid approach of statistical outlier detection on the entire distribution of pixels followed by a level-of-detection cutoff for remaining pixels well within the bounds for expected noise between the datasets. Remaining uncertainties are primarily caused by speckle noise and terrain characteristics, with the biggest impact from slope. The following sections provide a detailed description of the change detection method for channels and hillslopes.

\subsubsection{Channels}

We know from field observations that large braided gravelbed channels in the study area (Fig. 1b) change rapidly with local incision and aggradation (natural and anthropogenic in the form of gravel mining) on the order of meters during the past decade. Outlines of the bank-to-bank active width of the primary channel branch were digitized from opensource satellite imagery from Bing ${ }^{\mathrm{TM}}$ and GoogleEarth ${ }^{\mathrm{TM}}$. We buffered the resulting channels by $-60 \mathrm{~m}$ (upper limit of gridded SRTM-C resolution). This means we only use the wide ( $>120 \mathrm{~m}$ ), non-vegetated channel reaches from Río Toro and Río Grande where there has been recent aggradation and incision.

Change mapping was done by separating the in-channel $d h$ values into bins of contributing error factors (local relief and TanDEM-X individual scene consistency) and applying 5th and 95th percentile cutoffs to each bin, thus only taking the top (positive equals aggradation) and bottom (negative equals incision) $5 \%$ of outliers. We first used the TanDEM$\mathrm{X}$ WAM to remove the untrustworthy $d h$ pixels where coherence was lost three or more times (Wessel, 2018). Because gravel-bed channels represent a low-slope environment with no vegetation and we are only measuring wide valleys, we assumed that DEM errors from SRTM-C and TanDEM$\mathrm{X}$ were restricted to random speckle noise. Nonetheless, to account for steeper areas with potentially more error from phase unwrapping, we separated $d h$ into relief bins using the pixels' $500 \mathrm{~m}$ radius relief values. We also separated $d h$ by the TanDEM-X consistency and height error masks (Figs. S2 and S3). Taken together, $d h$ pixels in high-relief, high-height error, and low-consistency bins required greater magnitudes to avoid noise cutoffs than vice versa. A minimum-levelof-detection approach (Lane et al., 2003) was taken as the RMSE of the entire $d h$ map on low-slope (similar to channel slope) areas. In a final step, all remaining in-channel $d h$ values below this RMSE cutoff were removed as likely noise. Volume changes are calculated from the sum of the pixel area $\left(900 \mathrm{~m}^{2}\right)$ multiplied by vertical change, with uncertainties taken as the level-of-detection RMSE and propagated via Eq. (15) in Lane et al. (2003).

\subsubsection{Entire landscape}

When considering $d h$ over the entire landscape, we include far more uncertainties related chiefly to steeper terrain. Thus, the error must be handled differently than for strictly lowslope pixels (in-channel). First, a corrected $d h$ map for the entire study area was generated. Similar to channel mapping, low-coherence pixels were removed with the WAM and $d h$ was separated into bins of slope, height error, and consistency to retrieve only the top and bottom $5 \%$ of outliers in each bin set. The level-of-detection cutoff was taken as the RMSE across the entire landscape, which was almost entirely stable terrain, and remaining $d h$ values below this cutoff were eliminated.

At this stage, a great many lone and patchy $d h$ values remained. Given this, it was not possible to automatically identify areas of change that were only a small number of pixels in size. Interested in large-scale changes, likely not associated with a single pixel, we sought connected pixels showing all up or all down vertical motion. To winnow the potential change pixels, we applied binary opening with a 1-pixel radius circular kernel, thus removing many unconnected outliers and small patches. Next, we took the summed $d h$ of each separate patch. It was assumed that the majority of patches, and thus the majority of summed values, were remaining noise in the difference map, whereas signal should be spatially coherent and largely positive or negative. Therefore, by applying a standard deviation cutoff over summed patches (here we used $1 \sigma$, though this can be easily set for testing), we removed a vast majority of remaining pixels and only kept the largest outliers. This limited the method to only assessing the largest coherent vertical changes in the landscape but eliminated the possibility of misidentifying change that was in fact noise. These remaining patches can be explored in map view and compared with satellite or historical imagery for further confirmation and analysis. 

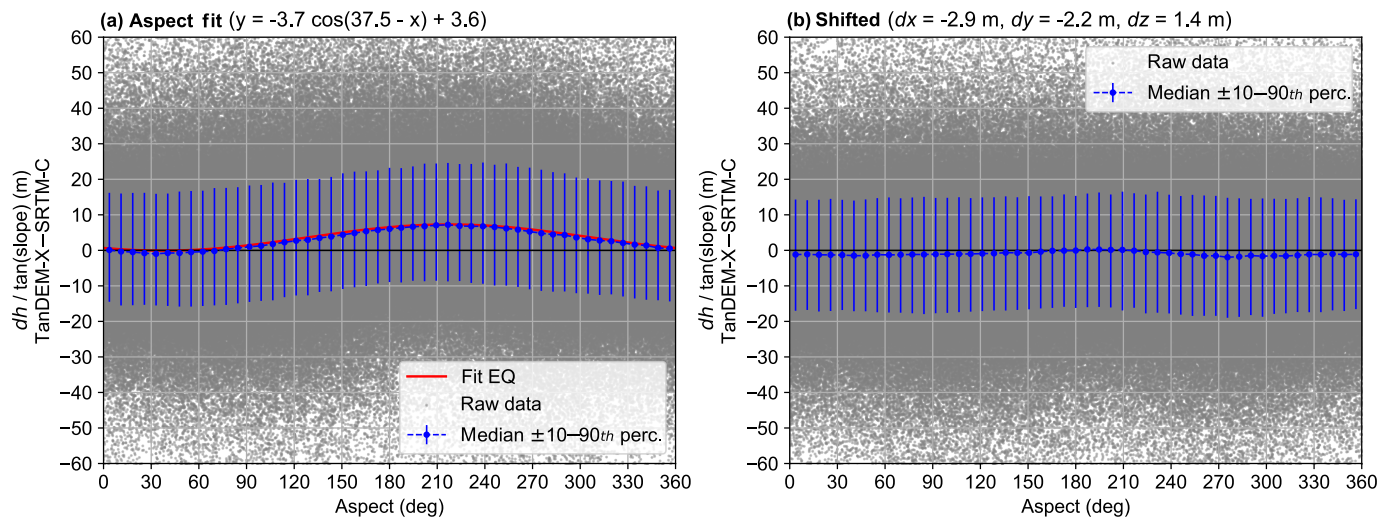

Figure 2. Relationship of $d h$ (normalized by the tangent of the slope) to aspect (a) before and (b) after co-registration and bilinear resampling of SRTM-C. We fit to Eq. (1) on all raw data. Note the close match between equation fit and median values. The cosine relationship in (a) is caused by overestimation of the SRTM-C on NE-facing aspects (peaking at $\sim 60^{\circ}$ ) and underestimation on SW-facing aspects (peaking at $\left.\sim 220^{\circ}\right)$. The resulting $(d x, d y)$ shift vector is directed SW.

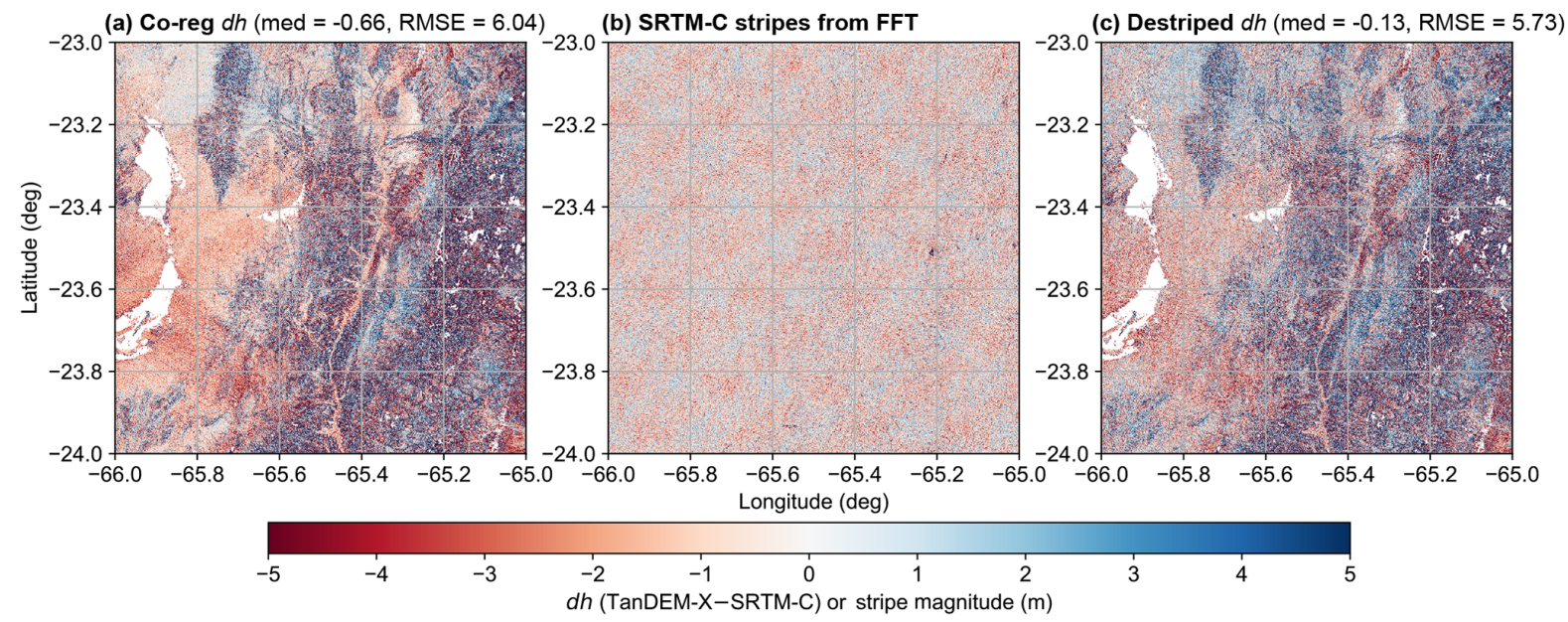

Figure 3. One iteration of FFT destriping from one tile $\left(24^{\circ} \mathrm{S}, 66^{\circ} \mathrm{W}\right)$. Both median and RMSE improve from (a) the co-registered map to (c) the destriped map. Stripes removed by FFT are shown in (b). Note that (c) is not the final corrected map as the iteration was run twice more before RMSE began to converge at a $5 \%$ tolerance level. Voids (white space) are untrustworthy pixels removed by TanDEM-X WAM cutoff prior to destriping.

\section{Results}

\subsection{Correction steps}

Co-registration of SRTM-C to TanDEM-X revealed $X-$ $Y$ shifts of $\sim 1 / 10$ of a pixel $(\sim 3.7 \mathrm{~m})$. Although minor $Z$ shifts $(\sim 1 \mathrm{~m})$ were also determined and corrected during co-registration, these were not unique across entire tiles, but rather related to long-wavelength SRTM-C biases. The cosine fitting to $d h$ normalized by terrain slope can be seen in Fig. 2, whereas in map view the change is more subtle and difficult to discern.

In Fig. 3, we demonstrate one iteration of destriping for a single SRTM-C tile $\left(24^{\circ} \mathrm{S}, 66^{\circ} \mathrm{W}\right)$. It is apparent in the co-registered $d h$ map that a number of long- and short- wavelength shifts are affecting the tile. Using our FFT, statistical cutoffs, inverse transform, and stripe removal, the resulting $d h$ map has a much more uniform appearance and the median and RMSE are both reduced. This process was typically repeated 2-4 times per tile, until the RMSE began to converge. While topographic uncertainties remain in steep and high-relief regions, the overprinting biases are reduced.

Since we do not use an aggressive FFT filtering scheme, a number of patchy outliers remain. We attempted to correct these regions using blocked shifting (Fig. 4), shown in this case over three tiles covering the foreland and AltiplanoPuna Plateau region $\left(24-26^{\circ} \mathrm{S}, 66^{\circ} \mathrm{W}\right)$. After testing multiple block sizes, we preferred blocks with an edge length of $3.6 \mathrm{~km}$, since these provide a small enough area to correct 


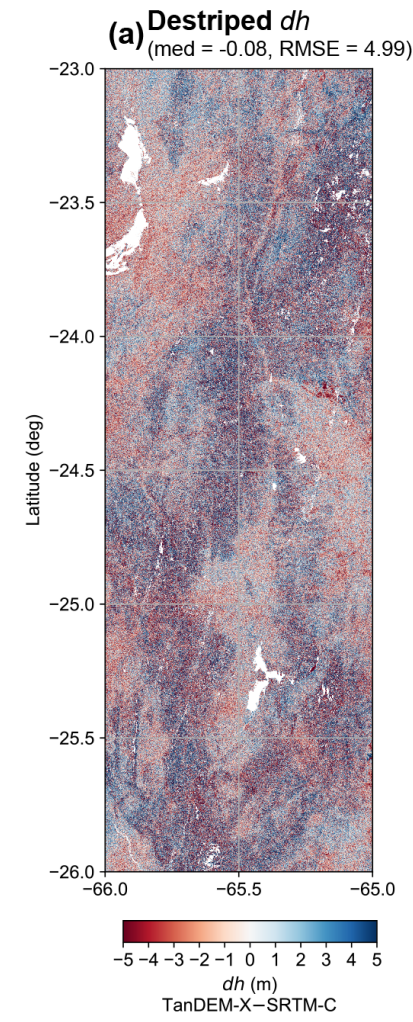

(b) Blocked medians

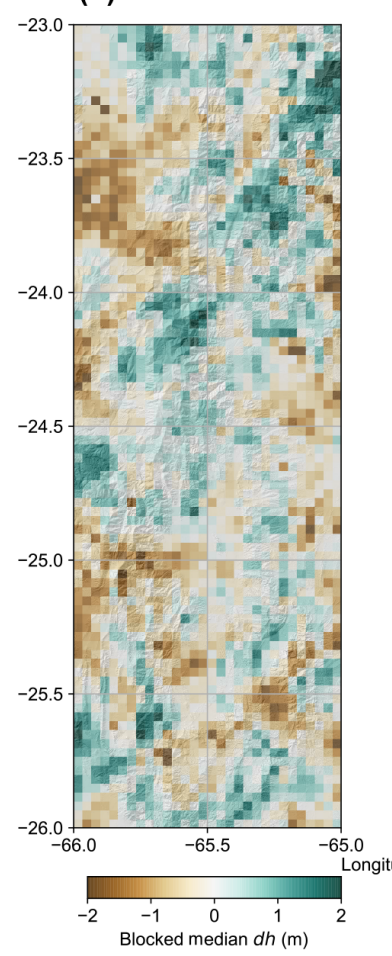

(c) Blocked medians

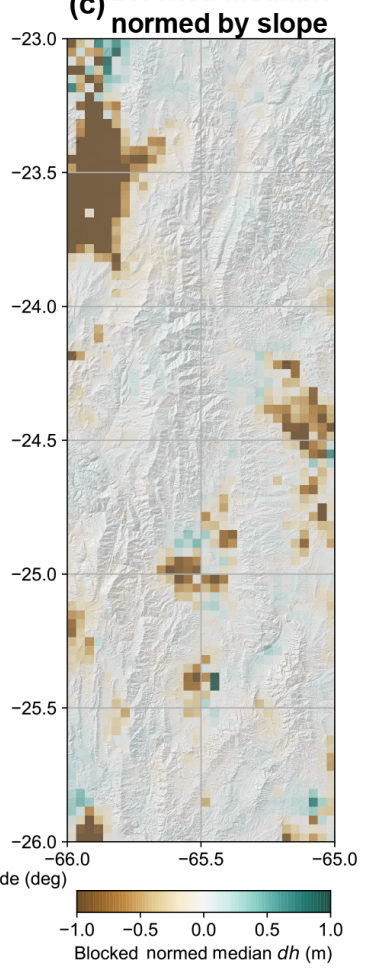

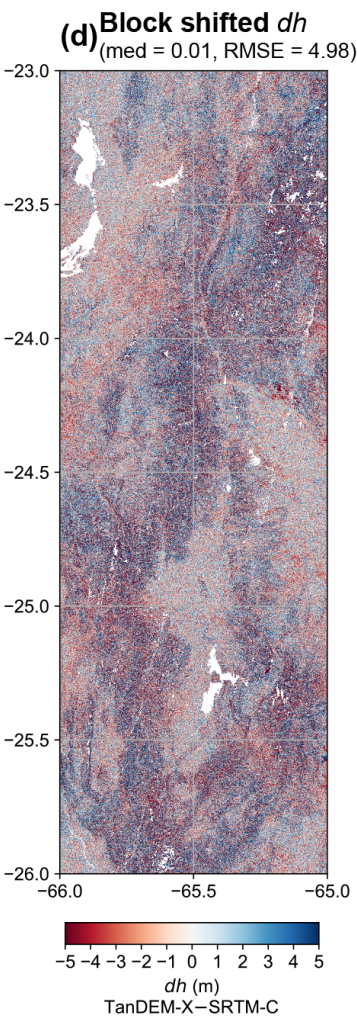

Figure 4. Blocked shifting on three destriped and merged tiles $\left(24-26^{\circ} \mathrm{S}, 66^{\circ} \mathrm{W}\right)$. Blocks are $3.6 \mathrm{~km}$ in height and width. The (a) destriped median and RMSE both improve slightly in (d) the final shifted $d h$ map. Note that the original blocked medians (b) show a slight pattern resembling the long-wavelength stripe bias from SRTM-C. In (c) we have normalized the median shifts by the median slope values, so as not to overcorrect the steeper regions with higher uncertainties. The color scheme is changed for (b) and (c), and the scale of (c) is half the width of (b) since it only extends to the maximum allowable shift of $\pm 1 \mathrm{~m}$. Scales and color scheme in (a) and (d) are identical. Voids (white space) are untrustworthy pixels removed by TanDEM-X WAM cutoff prior to median calculation.

highly localized inconsistencies, while also being far greater in size than the largest vertical changes we would expect in the landscape.

\subsubsection{Comparison of correction steps}

Since stacked histograms are difficult to interpret and larger magnitude outliers are fewer in number and thus obscured, we plotted the normalized bin percentage difference of $d h$ in each step of correction (Fig. 5). Co-registration mostly caused a mean shift in the distribution. Moving to destriping, the number of pixels at high outlier values went down significantly ( $>20 \%$ drop in $\pm 15-20 \mathrm{~m}$ bins) and there was some $(\sim 10 \%)$ increase in bins $\pm 5 \mathrm{~m}$, whereas the number of values close to zero $d h$ decreased. This represents an overall redistribution of error from the SRTM-C orbital biased patterns (Fig. 3) to a more uniform spatial pattern (Fig. 4). The final blocked shifting caused very little overall change in the distribution, which was mostly in the form of another mean shift (this time directed the other way from co-registration). These effects can also be seen in a QQ-plot of each subsequent correction step (Fig. 6), where co-registration caused a mean shift and some outlier reduction, de-striping had a large effect on narrowing the distribution at the tails, and blocked shifting again had a minimal effect on narrowing the distribution at the most extreme outliers. In all cases, the median value ( 0.5 quantile) moved closer to zero. Overall, these plots indicate the importance of SRTM-C correction and of the destriping step in particular prior to using TanDEM-X-SRTM$\mathrm{C} d h$ maps for change mapping.

\subsection{Areas of change}

As discussed in the methods, we separated potential change identification and measurement from corrected (coregistered, destriped, block shifted) $d h$ maps between the inchannel pixels and the entire landscape.

\subsubsection{Channels}

Binning corrected in-channel $d h$ and cutting off any remaining outliers within the low-slope RMSE of $\sim 3 \mathrm{~m}$ reduced the data density significantly by cutting out any pixels within expected noise. The potential signal pixels were then plotted 

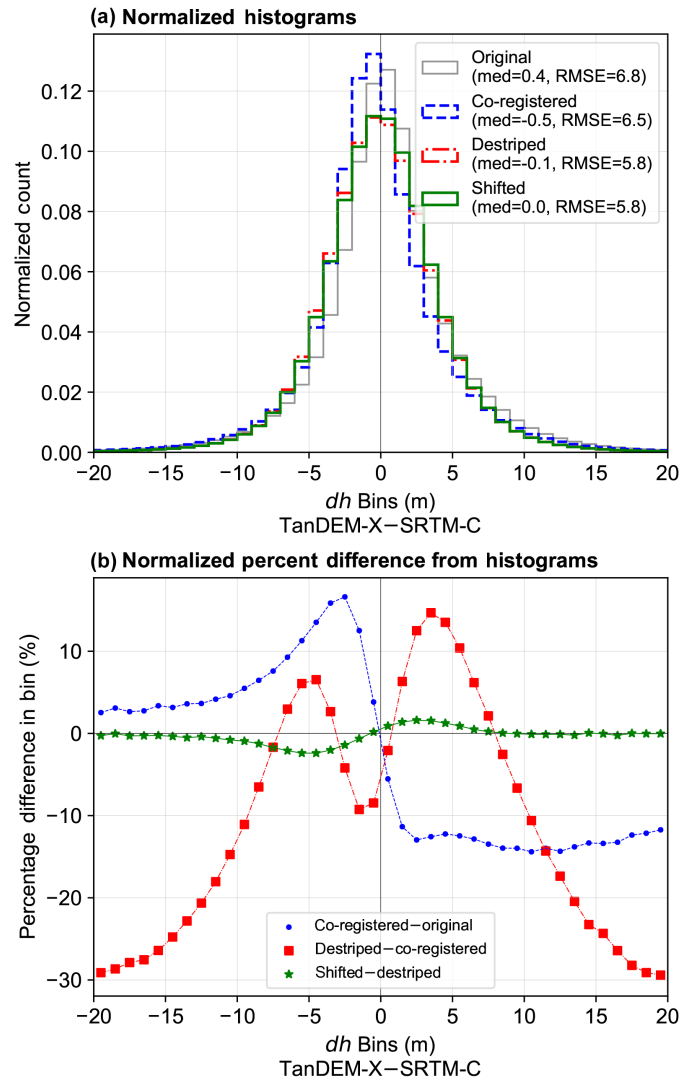

Figure 5. Characteristic (a) stacked histograms and (b) normalized percentage bin difference from three tiles merged and processed $\left(24-26^{\circ} \mathrm{S}, 66^{\circ} \mathrm{W}\right)$. Though it is difficult to interpret the histograms, plotting their difference (normalized by bin count) as percentage change between successive steps demonstrates the shifting of the median to near zero and the reduction in outliers.

atop longitudinal profiles from the Río Toro and Río Grande (Fig. 7). The point clouds of $d h$ values were colored with a Gaussian kernel density estimate (KDE) to demonstrate the denser (warmer colors) versus sparser (cooler colors) zones of measurement. The density is displayed as percentiles of the full distribution of the 2-D KDE of $d h$ from both channels. Turning to map view, we can observe the location of these pixels in the channel and their relation to local characteristics, upstream factors, and anthropogenic tampering (Fig. 8).

\subsubsection{Entire landscape}

To be mapped as true vertical change, an area in the greater landscape must be significantly large and coherently positive or negative since many of the pure noise patches are $>10$ pixels in size $\left(>0.01 \mathrm{~km}^{2}\right)$. Furthermore, the individual pixels must show significant height changes above the overall RMSE of $\sim 6 \mathrm{~m}$ and outlier cutoffs in each bin, which in steeper bins may be $>10 \mathrm{~m}$. Examining results in map view

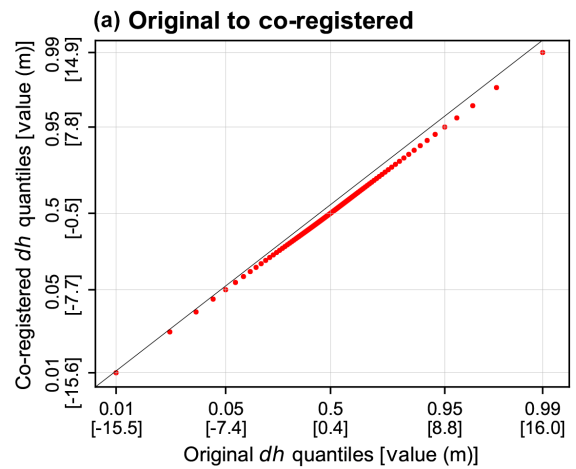

(b) Co-registered to destriped

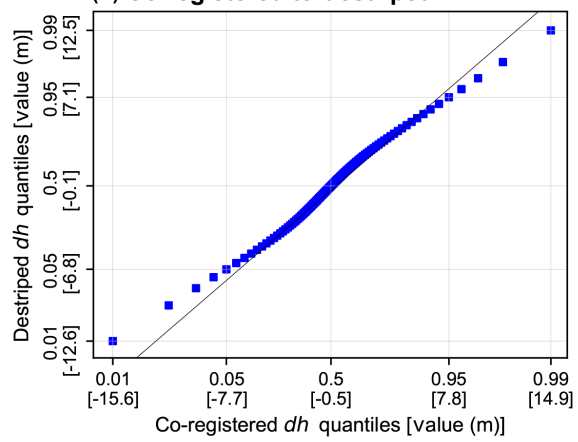

(c) Destriped to block shifted

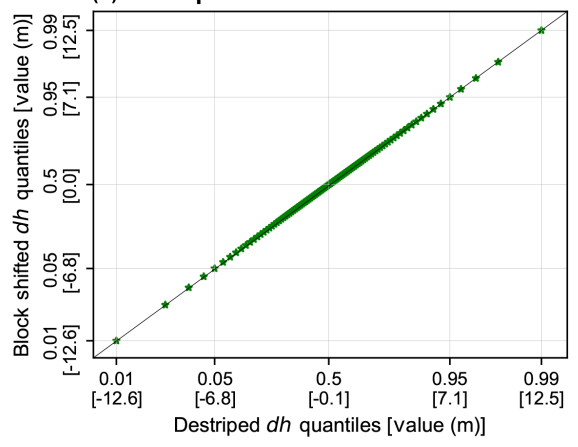

Figure 6. Quantile-quantile (QQ) plots showing the difference between each successive correction step from three tiles merged and processed $\left(24-26^{\circ} \mathrm{S}, 66^{\circ} \mathrm{W}\right)$. (a) Original to co-registered, (b) coregistered to destriped, and (c) destriped to block shifted. We note that co-registration and destriping have the greatest effect on zeromedian shifting and narrowing the outliers. The quantiles $(0.01$, $0.05,0.5,0.95$, and 0.99 ) and their respective values are indicated on each axis to highlight this effect.

(Fig. 9) allows assessment of the potential true signal versus noise. At this stage it is necessary to include auxiliary data from field knowledge or remote sources like aerial or satellite imagery (e.g., GoogleEarth ${ }^{\mathrm{TM}}$ ). Our method was able to identify one major landslide in the study area (Fig. 9d); however, most other measurements are remaining large artifacts attributable to both the SRTM-C and TanDEM-X. Low-coherence zones that may represent change between the TerraSAR-X and TanDEM-X contributing scene collection 

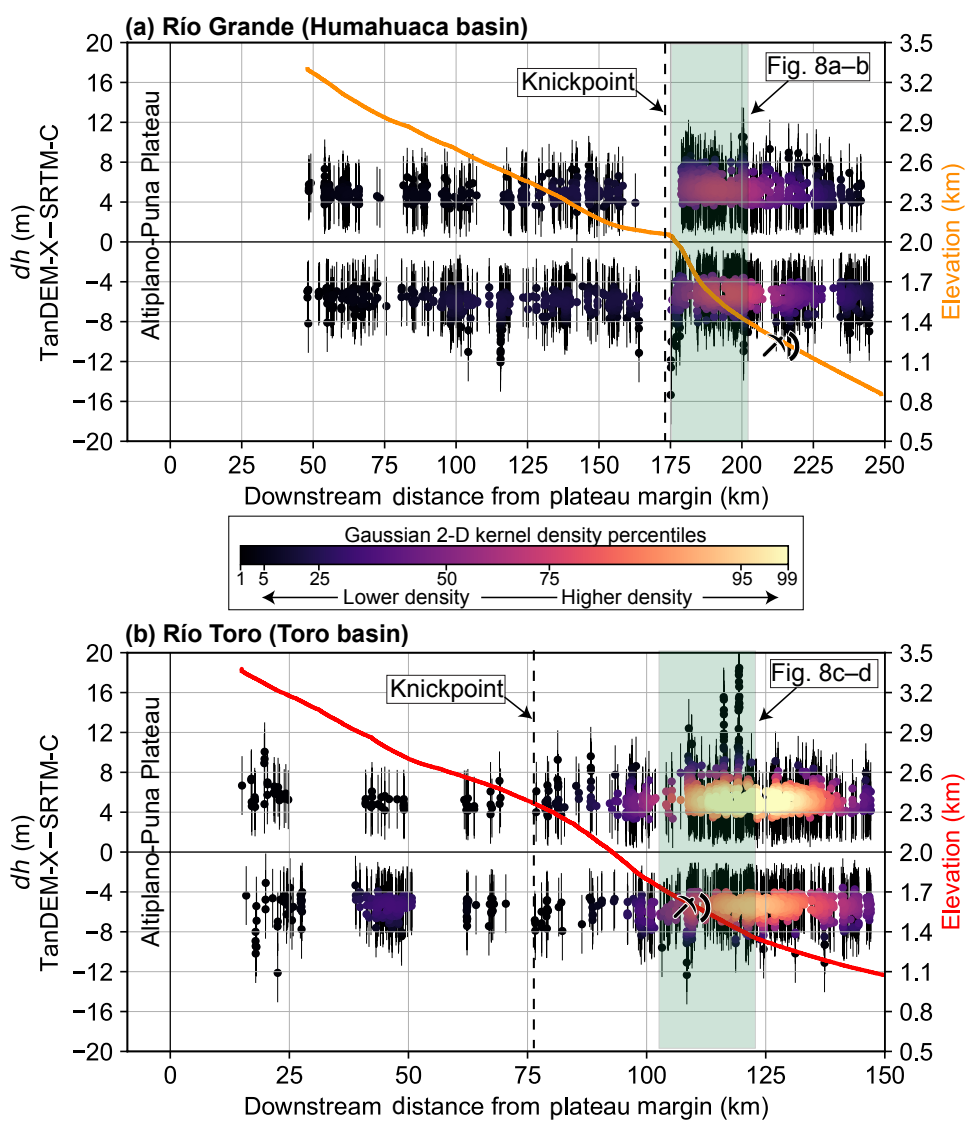

Figure 7. Longitudinal profiles of (a) Río Grande and (b) Río Toro overlain with the point cloud of the potential $d h$ signal (pixels outside of the range of expected noise). Error bars are RMSE from low-slope $\left(<5^{\circ}\right)$ terrain outside of the channel area. Each $d h$ point cloud is colored by probability density from a Gaussian 2-D KDE to show the denser (warmer) versus sparser (cooler) reaches. The KDE is scaled over all measurements from both channels and relative percentiles of the full distribution are used to highlight denser zones, particularly in (b) Río Toro. Note the $x$-axis range is $100 \mathrm{~km}$ greater for the longer Río Grande, despite the same axis scaling. The color scheme for elevation profiles on right axes matches the map-view color of each channel in Fig. 1b. The knickpoint in Río Grande is caused by the large Del Medio fan (Savi et al., 2016), whereas the origin in Río Toro is tectonic, caused by the Gólgota Fault (Marrett et al., 1994; Hilley and Strecker, 2005). In both cases, the majority of the $d h$ signal appears downstream of the knickpoint. The map view of green highlighted regions is shown in Fig. 8.

(Fig. 9b and c) are necessarily removed in the WAM cutoff prior to binning.

\section{Discussion}

\subsection{Necessity of correction steps}

The original SRTM-C is plagued by numerous terrain- and sensor-specific errors and biases (e.g., Carabajal and Harding, 2006; Gorokhovich and Voustianiouk, 2006; Van Niel et al., 2008; Gallant and Read, 2009; Yamazaki et al., 2017). Despite reprocessing of the original data in the new NASADEM product, many of these errors remain (Crippen et al., 2016). On the other hand, the newer TanDEM-X apparently has far fewer biases related to satellite geometry, and most of the error is restricted to terrain characteristics like slope and vegetation, though results are still nascent (e.g., Baade and Schmullius, 2016; Purinton and Bookhagen, 2017; Wessel et al., 2018). Our correction steps do not seek to eliminate bias related to terrain characteristics at the scale of a few hundred meters, but rather to correct large-scale biases related to primarily the SRTM-C at scales of several hundred meters to kilometers. Perhaps this reduction in bias is most obvious in the map view of the subsequent $d h$ patterns between processing steps (Figs. 3a to 4a to Fig. 4d), but we also show statistically that these steps lead to a narrowing of the distribution and centering of the differences on zeromedian (Figs. 5 and 6). We assume that the vast majority of the pixels (outside of the cryosphere) should be unchanged over 15 years, and thus median shifts between the datasets at large scales are biases in need of correction.

Co-registration indicates NE-facing aspects are overestimated by the SRTM-C causing a negative excursion in the 


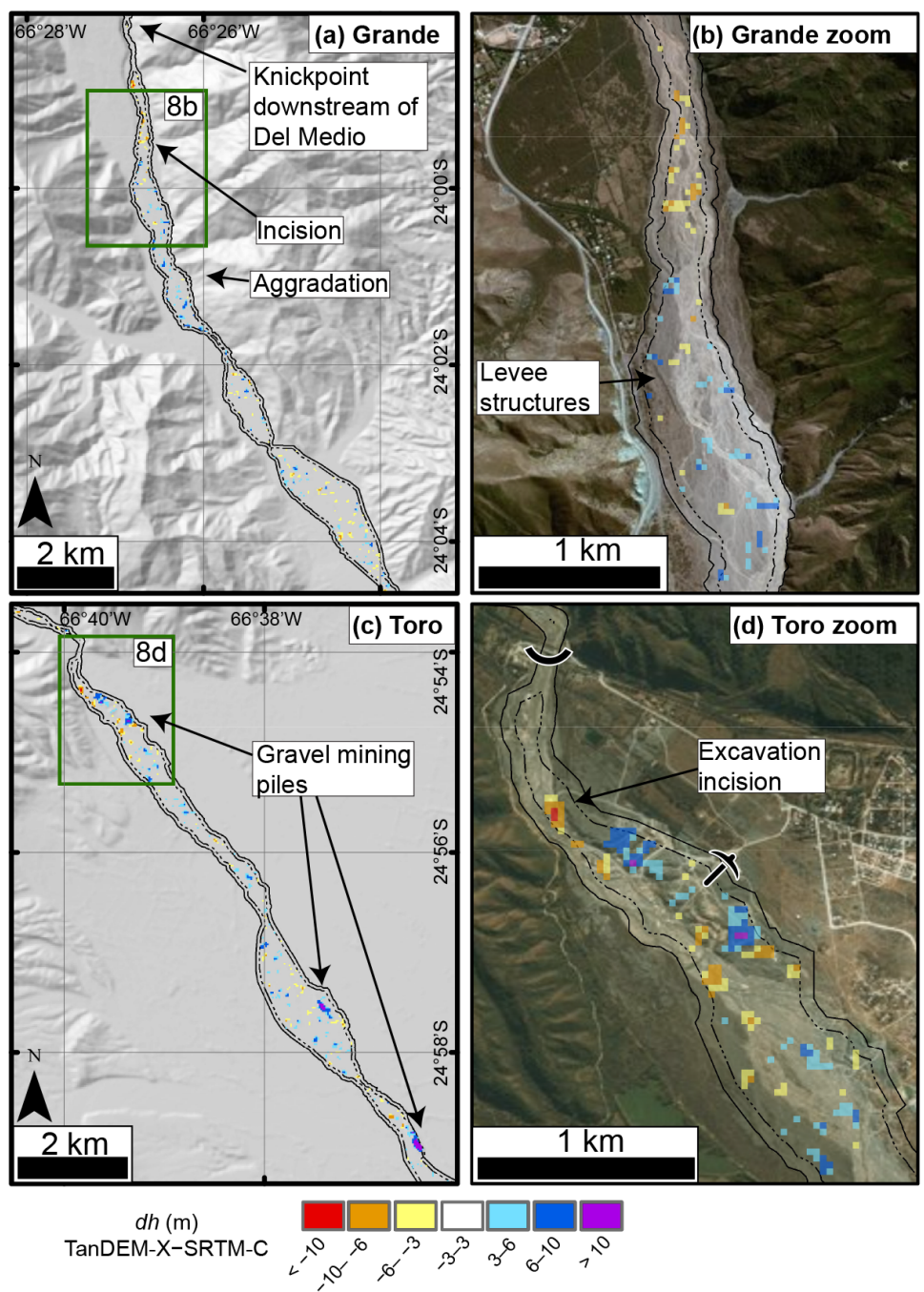

Figure 8. Map views of the in-channel $d h$ measurements for Río Grande (a) and Río Toro (c) highlighted in the longitudinal profiles in Fig. 7. For location of each map refer to Fig. 1c. More details are shown in zoomed-in images of the in-channel $d h$ measurements in (b) and (d). The solid outline is the digitized bank-to-bank channel and the stippled line is the $-60 \mathrm{~m}$ buffer area of measurement. We note large areas of incision related to the steep and narrow channel downstream of the Del Medio fan and knickpoint in Río Grande (a), immediately followed by a zone of aggradation with levee structures to direct gravels (b). For Río Toro (c) we highlight the anthropogenic influence of gravel mining generating large piles and also causing incision due to local excavation (d).

cosine fit, whereas SW-facing aspects are underestimated and thus the $d h$ compared to TanDEM-X is positive. This error mostly affects higher slopes (Nuth and Kääb, 2011), which is the reason for the normalization of $d h$ by the tangent of the slope. The directions of bias correspond to the look direction orthogonal to the SRTM-C descending path and parallel to the ascending path. This indicates that the source of this bias is the SRTM-C, as reported by previous authors (Bourgine and Baghdadi, 2005; Gorokhovich and Voustianiouk, 2006; Shortridge and Messina, 2011), and not TanDEM-X. A shift - accompanied by bilinear resampling of just $\sim 3.7 \mathrm{~m}$ (magnitude $a$ of Eq. 1 fit) to the SW rectifies this aspect bias.
As opposed to Yamazaki et al. (2017), we do not set a user-defined ratio for FFT destriping, but rather use statistical "shaving off" of only the outlier stripe noise until the data converge. This conservative approach retains the true topographic signal at the expense of remaining stripe noise. In the case of more aggressive FFT filtering, using lower percentiles for the ratio cutoff and more strict RMSE convergence requirements, the actual topography began to filter out of the $d h$ maps (Fig. S11), which, as stated, is not the aim of our orbital bias correction steps and would lead to the inclusion of artificial (i.e., FFT generated) $d h$ measurements.

Remaining stripe noise is apparent in Fig. 4b, where the blocked medians resemble the original long-wavelength 

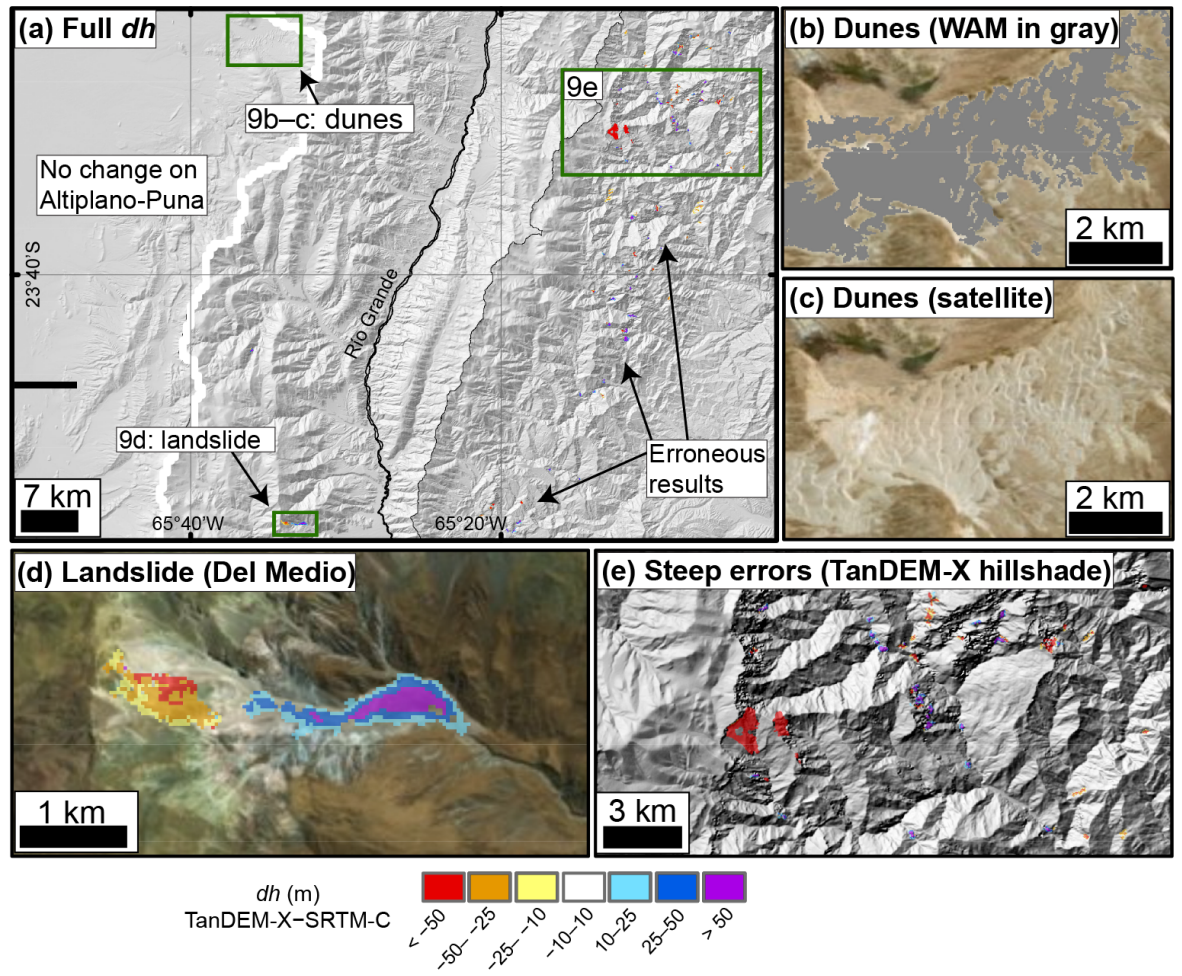

Figure 9. (a) Map view of landscape-wide $d h$ identification. For location refer to Fig. 1c. Our method returns little change on the low-erosion Altiplano-Puna. The dunes (b-c) are not identified since they are masked out using the TanDEM-X auxiliary WAM as low-coherence zones. This indicates their rapid displacement between the TerraSAR-X and TanDEM-X scene collection. Our method is able to identify one major landslide (d) in the Del Medio catchment (Savi et al., 2016); however, there are many erroneous results in steep and vegetated zones to the east, shown in (e) over the TanDEM-X hillshade.

stripe pattern, though discontinuous. Despite the appearance in some areas of more negative values in the western parts of tiles (higher elevation, Altiplano-Puna Plateau), we do not find any clear relation between block medians and elevation at any block size or in any tile (see Sect. S3). Block shifting removes the remaining noise, but again we avoid correcting for strongly overprinting topographic biases related to slope by normalizing the block median $d h$ by median slope. Overall, these steps provide a more trustworthy $d h$ map, while respecting the inherent biases in radar-derived spaceborne DEMs.

\subsection{Potential change mapping}

For lower-slope regions (i.e., channels), the potential for change mapping is greater than in steeper areas. This is caused by the better agreement and lower vertical uncertainty of the two datasets in flatter, vegetation-free areas. In both channels, the largest density of measurements is found below the respective knickpoints. This corresponds to an order of magnitude increase in the 2-D KDE shown by the warm-colored patches in Fig. 7. In terms of the actual number of measurements (number of $d h$ pixels) per binned channel reach, Fig. S13 demonstrates this approximately 5- to 10- fold increase in the downstream reaches with a simple histogram. This result partially has to do with a narrower channel and thus less measurements available above the knickpoints (hence the numerous gaps in measurement in the upstream reaches); however, these results also appear to indicate that the most geomorphic work is happening downstream of the oversteepening point. This also coincides with a transition to a wetter environment in both cases.

The Río Toro has a particularly dense zone of measurements at the mountain front where naturally high rates of aggradation are enhanced by human gravel excavation and piling. On the other hand, in the Río Grande the downstream measurements are spread over a greater channel reach and thus appear less dense in the 2-D KDE (the measured Río Grande is $\sim 100 \mathrm{~km}$ greater in length than the Río Toro). Downstream of the knickpoint, Río Toro is in a net aggradation state with a corrected $d h$ volume of $0.81 \pm 0.15 \times 10^{6} \mathrm{~m}^{3}$, whereas for Río Grande the net state is incision with a volume of $-0.69 \pm 0.15 \times 10^{6} \mathrm{~m}^{3}$. In comparison, the precorrection volume in each case is $-1.18 \pm 0.12 \times 10^{6}$ and $2.80 \pm 0.11 \times 10^{6} \mathrm{~m}^{3}$ for Río Toro and Río Grande, respectively, thus indicating a flip in sign and reduction of magnitude following careful corrections applied prior to differencing. 
Locally, the aggrading and incising patches may be related to braided channel avulsion and subsequent rapid incision into the unconsolidated bed material during frequent highdischarge events brought by convective rainfall in the summer monsoon (Castino et al., 2016a, b, 2017). In map view (Fig. 8), we see that these automated measurements can be correlated with additional sources. For Río Grande, the steep knickpoint at the Del Medio fan (Savi et al., 2016; Schildgen et al., 2016) causes a major zone of incision immediately followed by aggradation where the material is deposited. Fieldwork has indicated that some of this incision is man-made, caused by attempted removal of aggrading material coming from the productive (e.g., debris flows see Savi et al., 2016) Del Medio catchment. Levee structures (Fig. 8b) are a testament to this tendency towards aggradation downstream of this extremely erosive fan. The cause of aggradation in the Río Toro is clearly enormous gravel piles being created just at and downstream of the mountain front. The volume of the large gravel pile indicated in Fig. 8d directly at the mountain front in Río Toro is $0.78 \pm 0.06 \times 10^{6} \mathrm{~m}^{3}$, with this growth between SRTM-C and TanDEM-X observed during field work over the past decade and from GoogleEarth ${ }^{\mathrm{TM}}$ historical imagery back to 2003. This is coupled with incision in the active channel upstream of the piles where gravel is being removed to prevent widespread aggradation.

In terms of rates of change, our minimum measurable $d h$ of $\pm 3 \mathrm{~m}$ corresponds to a rate of $\pm 0.2 \mathrm{~m} \mathrm{yr}^{-1}$, given the conservative 15 -year time difference between DEMs. This rate represents an average for the entire measurement period and assumes constant geomorphic change, whereas the true rates are more stochastic, following rainfall and anthropogenic activity variation. The area of greatest point density in the longitudinal profiles in Fig. 7 is centered at $\pm 5 \mathrm{~m}$, corresponding to a rate of $\pm 0.33 \mathrm{~m} \mathrm{yr}^{-1}$, with maximum rates of incision and aggradation, occurring at anthropogenic gravel piles and excavation sites, in excess of $\pm 0.5 \mathrm{~m} \mathrm{yr}^{-1}$. Human tampering is known to cause significant excursions from natural river dynamics (Kondolf, 1997; Grant, 2012), and we have shown that signals of excavation and piling are highlighted as abovethe-noise outliers. Previous studies have demonstrated similar rates over longer timescales (tens to hundreds of years) using more sparse measurements (e.g., Rinaldi and Simon, 1998; Rovira et al., 2005; Walter and Merritts, 2008; Comiti et al., 2011) and at shorter timescales ( $<5$ years) from meterscale lidar data (Lane et al., 2003; Wheaton et al., 2010). The identification and quantification of incision and aggradation have important implications for infrastructure and agriculture given that $60 \%$ of global sediment delivery to coasts originates in high mountain regions (Syvitski et al., 2005).

Mapping $d h$ signals across the entire landscape presents a greater challenge given the higher uncertainties on steeper more complex topography. Nevertheless, using the binning method, binary operations, and outlier selection removes a large portion of the noise from the corrected data. Our method displays very little change on the low-relief, low- slope Altiplano-Puna besides some salt flat areas that were not removed by the coherence masking from the TanDEM-X WAM. Remaining noise mapped as potential change is clear at the mountain front where steep slopes and heavy vegetation causes complication of accurate radar measurement. In many locations these erroneous patches correspond with low-amplitude or low-coherence zones also identified in the WAM. We were able to automatically map one landslide, previously reported on by Savi et al. (2016), in the Del Medio sub-catchment of the Humahuaca Basin using this method. This material likely contributes to the aggradation we see occurring downstream of the fan in the longitudinal profile (Fig. 7a) and in map view (Fig. 8a). The calculated detachment and deposit volumes from this massive earth movement are $-10.5 \pm 0.12 \times 10^{6}$ and $16 \pm 0.15 \times 10^{6} \mathrm{~m}^{3}$, respectively, with vertical land-level changes greater than $\pm 50 \mathrm{~m}$ associated with the break-off and lobe (Fig. 9d). These magnitudes of change show little difference in the pre- and postcorrected mapping, indicating (a) this is a localized region of good agreement between SRTM-C and TanDEM-X and (b) this large landslide can be identified in uncorrected difference maps.

The area of sand dunes, clearly visible as a low-coherence region from the TanDEM-X WAM in Figs. 1c and $9 \mathrm{~b}$ and $\mathrm{c}$, is not mapped as potential change since the coherence masking prior to binning eliminates this area from consideration. Examination of $d h$ in this region is very noisy since the TanDEM-X contains measurements spanning 5 years, thus causing completely different height inputs for the same pixel in many scenes. This indicates the potential of the WAM alone for mapping change on shorter timescales outside of very steep areas.

\subsection{Caveats of the data and method}

Spaceborne DEMs present significant challenges for accurate height measurements, though, until lidar or submeter satellite data become more widespread and cheaper (Passalacqua et al., 2015), they are the only option in many study areas. On the other hand, unmanned aerial vehicles and point clouds generated using structure-from-motion technology could already provide a viable alternative (Javernick et al., 2014; Cook, 2017), but applying these methods at the scale of entire catchments or over tens of kilometers of river reaches is not feasible. Previously, $d h$ measurement from space has been primarily focused on the cryosphere (e.g., Berthier et al., 2006; Nuth and Kääb, 2011; Neelmeijer et al., 2017) due to limitations in data accuracy. Certainly radar data are more adequate than optical data (e.g., Fisher et al., 2013; Purinton and Bookhagen, 2017) for the case of unconsolidated sediment, particularly since different penetration depths do not affect measurement (Rignot et al., 2001; Rossi et al., 2016), assuming limited vegetation.

Here we have demonstrated the potential of new highaccuracy datasets such as TanDEM-X to correct outstand- 
ing biases in the SRTM-C and potentially contribute to land-level change mapping and measurement over previously unattainable scales. Given remaining noise in the datasets, change mapping is limited to large areas of coherent change (e.g., massive landslides) or specific low-slope areas of interest such as wide gravel-bed rivers. In any case, field data (e.g., repeat total station or GPS surveys), field knowledge (e.g., via observations of incising reaches or roads damaged by aggrading channels), and/or auxiliary data (e.g., GoogleEarth ${ }^{\mathrm{TM}}$ historical imagery change mapping) are necessary for accurate assessment of the location of true change signals versus noise. Further, the magnitude of change must be significantly above the expected uncertainty between DEMs, which in the case of SRTM-C and TanDEM-X is as low as $\sim 3 \mathrm{~m}$ on flat, sparsely vegetated terrain, and increasing with slope and topographic complexity. We posit that these correction steps may also be applied to cryospheric studies; however, radar penetration would need to be carefully considered first as this may exceed $d h$ signals.

\section{Conclusions}

In this study we have presented a novel use of two nearglobal spaceborne DEMs (SRTM-C and TanDEM-X) separated by $\sim 15$ years to measure land-level changes in the south-central Andes in northwestern Argentina. Previous measurement of land-level changes at the scale of entire mountain belts has been restricted to the cryosphere, where the signal of snow and ice change outweighs the noise associated with DEMs used for differencing (typically ASTER or single TerraSAR-X and TanDEM-X CoSSC DEMs). On the other hand, studies outside of the cryosphere have relied on high-accuracy meter to submeter data at much smaller scales to measure height changes in rivers and hillslopes. Using the TanDEM-X DEM as a control surface, we corrected long-standing SRTM-C errors related to orbital biases. We then successfully differenced the two datasets to identify and quantify land-level changes outside of expected noise caused by radar DEM speckle and other terrain-dependent errors, increasing with steep and complex topography. Noise from imperfect datasets continues to hinder signal detection in lowmagnitude geomorphic change detection; however, this study continues to push the envelope of the potential for change mapping using the data currently available to many scientists.

Our method is useful for the case of large gravel-bed rivers where the width far exceeds SRTM-C 1 arcsec resolution considerations. In such flat, vegetation-free environments it is useful to analyze the river alone and not include additional uncertainties brought by increasing slopes and dense vegetation. For these steeper regions, the use of greater outlier cutoffs and the necessity for large and coherent patches of landlevel change, both to remove the majority of noise, limit the method to only very large earth movements. In either case, only signals outside of expected noise can be confidently identified, which in the case of gravel-bed rivers typically fall in the realm of human tampering. From the TanDEM$\mathrm{X}$ auxiliary data alone it is also possible to identify regions that changed during TanDEM-X collection (2010-2015) using the water indication mask; however, this does not provide quantifiable change.

Overall, the use of relatively coarse ( $1 \mathrm{arcsec})$ spaceborne DEMs to derive land-level changes benefits from higheraccuracy radar-derived data, whereas the use of optical data is limited to submeter-resolution satellites. The application of this method to other regions around the world could indicate previously unmapped vertical changes. In the future, both the SRTM-C and TanDEM-X will continue to be used as snapshots of the earth's surface separated by over a decade and thus useful for differencing against newer datasets yet to be developed to continue measuring vertical change outside of the cryosphere.

Code and data availability. Python codes for co-registration, FFT destriping, blocked shifting, and potential change mapping are available on GitHub at https://github.com/UP-RS-ESP/ TanDEM-SRTM-dh (Purinton, 2018). The SRTM-C updated NASADEM tiles can be found at https://e4ft101.cr.usgs.gov/ provisional/MEaSUREs/NASADEM/ (US Government, 2018). TanDEM-X data are only available from DLR commercially for the time being.

Supplement. The supplement related to this article is available online at: https://doi.org/10.5194/esurf-6-971-2018-supplement.

Author contributions. BB and BP defined the project. BP carried out the analysis, produced the figures, and wrote the manuscript. $\mathrm{BB}$ provided funding, guidance in data analysis, and manuscript edits.

Competing interests. The authors declare that they have no conflict of interest.

Acknowledgements. The authors thank the DLR for TanDEM$\mathrm{X}$ DEMs received through grants DEM_CALVAL1028 for Benjamin Purinton and DEM_GEOL1762 for Stephanie Olen. Additional funding was sourced from DFG Funded IRTG-StRATEGy (IGK2018) and NEXUS funded through the MWFK Brandenburg, Germany, both for Bodo Bookhagen. We acknowledge the support of the Open Access Publishing Fund of the University of Potsdam.

Edited by: Simon Mudd

Reviewed by: two anonymous referees 


\section{References}

Arrell, K., Wise, S., Wood, J., and Donoghue, D.: Spectral filtering as a method of visualising and removing striped artefacts in digital elevation data, Earth Surf. Proc. Land., 33, 943-961, 2008.

Baade, J. and Schmullius, C.: TanDEM-X IDEM precision and accuracy assessment based on a large assembly of differential GNSS measurements in Kruger National Park, South Africa, ISPRS J. Photogram. Remote Sens., 119, 496-508, 2016.

Bagnardi, M., González, P. J., and Hooper, A.: High-resolution digital elevation model from tri-stereo Pleiades-1 satellite imagery for lava flow volume estimates at Fogo Volcano, Geophys. Res. Lett., 43, 6267-6275, https://doi.org/10.1002/2016g1069457, 2016.

Berthier, E., Arnaud, Y., Vincent, C., and Rémy, F.: Biases of SRTM in high-mountain areas: Implications for the monitoring of glacier volume changes, Geophys. Res. Lett., 33, L08502, https://doi.org/10.1029/2006gl025862, 2006.

Berthier, E., Arnaud, Y., Kumar, R., Ahmad, S., Wagnon, P., and Chevallier, P.: Remote sensing estimates of glacier mass balances in the Himachal Pradesh (Western Himalaya, India), Remote Sens. Environ., 108, 327-338, https://doi.org/10.1016/j.rse.2006.11.017, 2007.

Bessette-Kirton, E. K., Coe, J. A., and Zhou, W.: Using Stereo Satellite Imagery to Account for Ablation, Entrainment, and Compaction in Volume Calculations for Rock Avalanches on Glaciers: Application to the 2016 Lamplugh Rock Avalanche in Glacier Bay National Park, Alaska, J. Geophys. Res.-Earth, 123, 622-641, https://doi.org/10.1002/2017JF004512, 2018.

Bookhagen, B. and Strecker, M. R.: Orographic barriers, high-resolution TRMM rainfall, and relief variations along the eastern Andes, Geophys. Res. Lett., 35, L06403, https://doi.org/10.1029/2007gl032011, 2008.

Bookhagen, B. and Strecker, M. R.: Spatiotemporal trends in erosion rates across a pronounced rainfall gradient: Examples from the southern Central Andes, Earth Planet. Sc. Lett., 327-328, 97110, https://doi.org/10.1016/j.epsl.2012.02.005, 2012.

Booth, A. M., Roering, J. J., and Perron, J. T.: Automated landslide mapping using spectral analysis and highresolution topographic data: Puget Sound lowlands, Washington, and Portland Hills, Oregon, Geomorphology, 109, 132-147, https://doi.org/10.1016/j.geomorph.2009.02.027, 2009.

Bourgine, B. and Baghdadi, N.: Assessment of C-band SRTM DEM in a dense equatorial forest zone, Comptes Rendus Geoscience, 337, 1225-1234, 2005.

Brun, F., Berthier, E., Wagnon, P., Kääb, A., and Treichler, D.: A spatially resolved estimate of High Mountain Asia glacier mass balances from 2000 to 2016, Nat. Geosci., 10, 668-673, https://doi.org/10.1038/ngeo2999, 2017.

Carabajal, C. C. and Harding, D. J.: SRTM C-band and ICESat laser altimetry elevation comparisons as a function of tree cover and relief, Photogram. Eng. Remote Sens., 72, 287-298, 2006.

Castino, F., Bookhagen, B., and Strecker, M.: River-discharge dynamics in the Southern Central Andes and the 197677 global climate shift, Geophys. Res. Lett., 43, 679-687, https://doi.org/10.1002/2016GL070868, 2016a.

Castino, F., Bookhagen, B., and Strecker, M.: Rainfall variability and trends of the past six decades (1950-2014) in the subtropical NW Argentine Andes, Clim. Dynam., 3, 1049-1067, 2016b.
Castino, F., Bookhagen, B., and Strecker, M. R.: Oscillations and trends of river discharge in the southern Central Andes and linkages with climate variability, J. Hydrol., 555, 108-124, 2017.

Comiti, F., Da Canal, M., Surian, N., Mao, L., Picco, L., and Lenzi, M.: Channel adjustments and vegetation cover dynamics in a large gravel bed river over the last 200 years, Geomorphology, 125, 147-159, 2011.

Cook, K. L.: An evaluation of the effectiveness of low-cost UAVs and structure from motion for geomorphic change detection, $\mathrm{Ge}-$ omorphology, 278, 195-208, 2017.

Crippen, R., Buckley, S., Agram, P., Belz, E., Gurrola, E., Hensley, S., Kobrick, M., Lavalle, M., Martin, J., Neumann, M., Nguyen, Q., Rosen, P., Shimada, J., Simard, M., and Tung, W.: NASADEM global elevation model: methods and progress, ISPRS Int. Arch. Photogram. Remote Sens. Spat. Inform. Sci., XLI-B4, 125-128, https://doi.org/10.5194/isprs-archivesXLI-B4-125-2016, 2016.

Farr, T. G., Rosen, P. A., Caro, E., Crippen, R., Duren, R., Hensley, S., Kobrick, M., Paller, M., Rodriguez, E., Roth, L., Seal, D., Shaffer, S., Shimada, J., Umland, J., Werner, M., Oskin, M., Burbank, D., and Alsdorf, D.: The Shuttle Radar Topography Mission, Rev. Geophys., 45, RG2004, https://doi.org/10.1029/2005RG000183, 2007.

Fisher, G. B., Bookhagen, B., and Amos, C. B.: Channel planform geometry and slopes from freely available high-spatial resolution imagery and DEM fusion: Implications for channel width scalings, erosion proxies, and fluvial signatures in tectonically active landscapes, Geomorphology, 194, 46-56, https://doi.org/10.1016/j.geomorph.2013.04.011, 2013.

Gallant, J. and Read, A.: Enhancing the SRTM data for Australia, Proc. Geomorphomet., 31, 149-154, 2009.

Gardelle, J., Berthier, E., and Arnaud, Y.: Impact of resolution and radar penetration on glacier elevation changes computed from DEM differencing, J. Glaciol., 58, 419-422, https://doi.org/10.3189/2012JoG11J175, 2012.

Girod, L., Nuth, C., Kääb, A., McNabb, R., and Galland, O.: MMASTER: Improved ASTER DEMs for Elevation Change Monitoring, Remote Sensing, 9, 704, 2017.

Gorokhovich, Y. and Voustianiouk, A.: Accuracy assessment of the processed SRTM-based elevation data by CGIAR using field data from USA and Thailand and its relation to the terrain characteristics, Remote Sens. Environ., 104, 409-415, https://doi.org/10.1016/j.rse.2006.05.012, 2006.

Grant, G. E.: The Geomorphic Response of Gravel-Bed Rivers to Dams: Perspectives and Prospects, in: GravelBed Rivers, edited by: Church, M., Biron, P. M., and Roy, A. G., John Wiley \& Sons, West Sussex, UK, 165-181, https://doi.org/10.1002/9781119952497.ch15, 2012.

Hilley, G. E. and Strecker, M. R.: Processes of oscillatory basin filling and excavation in a tectonically active orogen: Quebrada del Toro Basin, NW Argentina, Geol. Soc. Am. Bull., 117, 887-901, 2005.

Hofton, M., Dubayah, R., Blair, J. B., and Rabine, D.: Validation of SRTM Elevations Over Vegetated and Non-vegetated Terrain Using Medium Footprint Lidar, Photogram. Eng. Remote Sens., 72, 279-285, https://doi.org/10.14358/pers.72.3.279, 2006.

Höhle, J. and Höhle, M.: Accuracy assessment of digital elevation models by means of robust statistical meth- 
ods, ISPRS J. Photogram. Remote Sens., 64, 398-406, https://doi.org/10.1016/j.isprsjprs.2009.02.003, 2009.

Hovius, N., Stark, C. P., and Allen, P. A.: Sediment flux from a mountain belt derived by landslide mapping, Geology, 25, 231234, 1997.

Huete, A., Justice, C., and Liu, H.: Development of vegetation and soil indices for MODIS-EOS, Remote Sens. Environ., 49, 224 234, 1994.

Jarvis, A., Reuter, H. I., Nelson, A., and Guevara, E.: Hole-filled SRTM for the globe Version 4, available from the CGIAR-CSI SRTM 90 m Database, available at: http://srtm.csi.cgiar.org (last access: 26 October 2018), 2008.

Javernick, L., Brasington, J., and Caruso, B.: Modeling the topography of shallow braided rivers using Structure-from-Motion photogrammetry, Geomorphology, 213, 166-182, 2014.

Kääb, A.: Remote sensing of mountain glaciers and permafrost creep, $\mathrm{PhD}$ Thesis, in: Schriftenreihe Physische Geographie, Department of Geography, Zurich, 266 pp., 2005.

Kondolf, G.: Hungry water: Effects of dams and gravel mining on river channels, Environ. Manage., 21, 533-551, https://doi.org/10.1007/s002679900048, 1997.

Krieger, G., Zink, M., Bachmann, M., Bräutigam, B., Schulze, D., Martone, M., Rizzoli, P., Steinbrecher, U., Walter Antony, J., De Zan, F., Hajnsek, I., Papathanassiou, K., Kugler, F., Rodriguez Cassola, M., Younis, M., Baumgartner, S., LópezDekker, P., Prats, P., and Moreira, A.: TanDEM-X: A radar interferometer with two formation-flying satellites, Acta Astronaut., 89, 83-98, https://doi.org/10.1016/j.actaastro.2013.03.008, 2013.

Lane, S. N., Westaway, R. M., and Murray Hicks, D.: Estimation of erosion and deposition volumes in a large, gravel-bed, braided river using synoptic remote sensing, Earth Surf. Proc. Land., 28, 249-271, 2003.

Marrett, R., Allmendinger, R., Alonso, R., and Drake, R.: Late Cenozoic tectonic evolution of the Puna Plateau and adjacent foreland, northwestern Argentine Andes, J. S. Am. Earth Sci., 7, 179-207, 1994.

Mason, J. and Mohrig, D.: Using Time-Lapse Lidar to Quantify River Bend Evolution on the Meandering Coastal Trinity River, Texas, USA, J. Geophys. Res.-Earth, 123, 1133-1144, https://doi.org/10.1029/2017JF004492, 2018.

Neelmeijer, J., Motagh, M., and Bookhagen, B.: High-resolution digital elevation models from single-pass TanDEM-X interferometry over mountainous regions: A case study of Inylchek Glacier, Central Asia, ISPRS J. Photogram. Remote Sens., 130, 108-121, https://doi.org/10.1016/j.isprsjprs.2017.05.011, 2017.

Nuimura, T., Fujita, K., Yamaguchi, S., and Sharma, R. R.: Elevation changes of glaciers revealed by multitemporal digital elevation models calibrated by GPS survey in the Khumbu region, Nepal Himalaya, 1992-2008, J. Glaciol., 58, 648-656, 2012.

Nuth, C. and Kääb, A.: Co-registration and bias corrections of satellite elevation data sets for quantifying glacier thickness change, The Cryosphere, 5, 271-290, https://doi.org/10.5194/tc-5-2712011, 2011.

Oskin, M. E., Arrowsmith, J. R., Corona, A. H., Elliott, A. J., Fletcher, J. M., Fielding, E. J., Gold, P. O., Garcia, J. J. G., Hudnut, K. W., Liu-Zeng, J., and Teran, O. J.: Near-field deformation from the El Mayor-Cucapah earthquake revealed by differential LIDAR, Science, 335, 702-705, 2012.
Passalacqua, P., Belmont, P., Staley, D. M., Simley, J. D., Arrowsmith, J. R., Bode, C. A., Crosby, C., DeLong, S. B., Glenn, N. F., Kelly, S. A., Lague, D., Sangireddy, H., Schaffrath, K., Tarboton, D. G., Wasklewicz, T., and Wheaton, J. M.: Analyzing high resolution topography for advancing the understanding of mass and energy transfer through landscapes: A review, Earth-Sci. Rev., 148, 174-193, https://doi.org/10.1016/j.earscirev.2015.05.012, 2015.

Paul, F.: Calculation of glacier elevation changes with SRTM: is there an elevation-dependent bias?, J. Glaciol., 54, 945-946, 2008.

Peduzzi, P., Herold, C., and Silverio, W.: Assessing high altitude glacier thickness, volume and area changes using field, GIS and remote sensing techniques: the case of Nevado Coropuna (Peru), The Cryosphere, 4, 313-323, https://doi.org/10.5194/tc-4-3132010, 2010.

Perroy, R. L., Bookhagen, B., Asner, G. P., and Chadwick, O. A.: Comparison of gully erosion estimates using airborne and ground-based LiDAR on Santa Cruz Island, California, Geomorphology, 118, 288-300, 2010.

Purinton, B.: SRTM-TanDEM-dh Github Repository, https://github. com/UP-RS-ESP/TanDEM-SRTM-dh, last access: 26 October 2018.

Purinton, B. and Bookhagen, B.: Validation of digital elevation models (DEMs) and comparison of geomorphic metrics on the southern Central Andean Plateau, Earth Surf. Dynam., 5, 211 237, https://doi.org/10.5194/esurf-5-211-2017, 2017.

Racoviteanu, A. E., Manley, W. F., Arnaud, Y., and Williams, M. W.: Evaluating digital elevation models for glaciologic applications: An example from Nevado Coropuna, Peruvian Andes, Global Planet. Change, 59, 110-125, https://doi.org/10.1016/j.gloplacha.2006.11.036, 2007.

Rexer, M. and Hirt, C.: Comparison of free high resolution digital elevation data sets (ASTER GDEM2, SRTM v2.1/v4.1) and validation against accurate heights from the Australian National Gravity Database, Aust. J. Earth Sci., 61, 213-226, https://doi.org/10.1080/08120099.2014.884983, 2014.

Rignot, E., Echelmeyer, K., and Krabill, W.: Penetration depth of interferometric synthetic-aperture radar signals in snow and ice, Geophys. Res. Lett., 28, 3501-3504, https://doi.org/10.1029/2000GL012484, 2001.

Rinaldi, M. and Simon, A.: Bed-level adjustments in the Arno River, central Italy, Geomorphology, 22, 57-71, 1998.

Rizzoli, P., Martone, M., Gonzalez, C., Wecklich, C., Tridon, D. B., Bräutigam, B., Bachmann, M., Schulze, D., Fritz, T., Huber, M., Wessel, B., Krieger, G., Zink, M., and Moreira, A.: Generation and performance assessment of the global TanDEM-X digital elevation model, ISPRS J. Photogram. Remote Sens., 132, 119139, 2017.

Rodríguez, E., Morris, C. S., and Belz, J. E.: A Global Assessment of the SRTM Performance, Photogram. Eng. Remote Sens., 72, 249-260, https://doi.org/10.14358/pers.72.3.249, 2006.

Rossi, C., Minet, C., Fritz, T., Eineder, M., and Bamler, R.: Temporal monitoring of subglacial volcanoes with TanDEM-X - Application to the 2014-2015 eruption within the Bárðarbunga volcanic system, Iceland, Remote Sens. Environ., 181, 186-197, https://doi.org/10.1016/j.rse.2016.04.003, 2016. 
Rovira, A., Batalla, R., and Sala, M.: Response of a river sediment budget after historical gravel mining (the lower Tordera, NE Spain), River Res. Appl., 21, 829-847, 2005.

Savi, S., Schildgen, T. F., Tofelde, S., Wittmann, H., Scherler, D., Mey, J., Alonso, R. N., and Strecker, M. R.: Climatic controls on debris-flow activity and sediment aggradation: The Del Medio fan, NW Argentina, J. Geophys. Res.-Earth, 121, 2424-2445, 2016.

Schildgen, T. F., Robinson, R. A., Savi, S., Phillips, W. M., Spencer, J. Q., Bookhagen, B., Scherler, D., Tofelde, S., Alonso, R. N., Kubik, P. W., Binnie, S. A., and Strecker, M. R.: Landscape response to late Pleistocene climate change in NW Argentina: Sediment flux modulated by basin geometry and connectivity, J. Geophys. Res.-Earth, 121, 392-414, 2016.

Schutz, B., Zwally, H., Shuman, C., Hancock, D., and DiMarzio, J.: Overview of the ICESat mission, Geophys. Res. Lett., 32, L21S01, https://doi.org/10.1029/2005GL024009, 2005.

Shortridge, A. and Messina, J.: Spatial structure and landscape associations of SRTM error, Remote Sens. Environ., 115, 1576-1587, https://doi.org/10.1016/j.rse.2011.02.017, 2011.

Sun, G., Ranson, K. J., Kharuk, V. I., and Kovacs, K.: Validation of surface height from shuttle radar topography mission using shuttle laser altimeter, Remote Sens. Environ., 88, 401-411, 2003.

Syvitski, J. P., Vörösmarty, C. J., Kettner, A. J., and Green, P.: Impact of humans on the flux of terrestrial sediment to the global coastal ocean, Science, 308, 376-380, 2005.

Tachikawa, T., Kaku, M., Iwasaki, A., Gesch, D. B., Oimoen, M. J., Zhang, Z., Danielson, J. J., Krieger, T., Curtis, B., Haase, J., Abrams, M., Crippen, R., and Carabajal, C.: ASTER global digital elevation model version 2 - summary of validation results, Tech. rep., Joint Japan - US ASTER Science Team, available at: http://www.jspacesystems.or.jp/ersdac/GDEM/ ver2Validation/Summary_GDEM_validation_report_final.pdf (last access: 26 October 2018), 2011.

Tadono, T., Ishida, H., Oda, F., Naito, S., Minakawa, K., and Iwamoto, H.: Precise Global DEM Generation by ALOS PRISM, ISPRS Ann. Photogram. Remote Sens. Spat. Inform. Sci., II-4, 71-76, https://doi.org/10.5194/isprsannals-ii-4-71-2014, 2014.
US Government: NASADEM MEaSUREs, available at: https: //e4ft101.cr.usgs.gov/provisional/MEaSUREs/NASADEM/, last access: 26 October 2018.

Van Niel, T. G., McVicar, T. R., Li, L., Gallant, J. C., and Yang, Q.: The impact of misregistration on SRTM and DEM image differences, Remote Sens. Environ., 112, 2430-2442, https://doi.org/10.1016/j.rse.2007.11.003, 2008.

Walter, R. C. and Merritts, D. J.: Natural streams and the legacy of water-powered mills, Science, 319, 299-304, 2008.

Wang, D. and Kääb, A.: Modeling glacier elevation change from DEM time series, Remote Sensing, 7, 10117-10142, 2015.

Wendleder, A., Wessel, B., Roth, A., Breunig, M., Martin, K., and Wagenbrenner, S.: TanDEM-X water indication mask: Generation and first evaluation results, IEEE J. Select. Top. Appl. Earth Obs. Remote Sens., 6, 171-179, 2013.

Wessel, B.: TanDEM-X Ground Segment - DEM Products Specification Document, EOC, DLR, Oberpfaffenhofen, Germany, Public Document TD-GS-PS-0021, available at: https: //tandemx-science.dlr.de/, last access: 26 October 2018.

Wessel, B., Huber, M., Wohlfart, C., Marschalk, U., Kosmann, D., and Roth, A.: Accuracy Assessment of the Global TanDEM-X Digital Elevation Model with GPS Data, ISPRS J. Photogram. Remote Sens., 239, 171-182, 2018.

Wheaton, J. M., Brasington, J., Darby, S. E., and Sear, D. A.: Accounting for uncertainty in DEMs from repeat topographic surveys: improved sediment budgets, Earth Surf. Proc. Land., 35, 136-156, 2010.

Yamazaki, D., Ikeshima, D., Tawatari, R., Yamaguchi, T., O'Loughlin, F., Neal, J. C., Sampson, C. C., Kanae, S., and Bates, P. D.: A high accuracy map of global terrain elevations, Geophys. Res. Lett., 44, 5844-5853, https://doi.org/10.1002/2017GL072874, 2017.

Zwally, H., Schutz, R., Bentley, C., Bufton, J., Herring, T., Minster, J., Spinhirne, J., and Thomas, R.: GLAS/ICESat L2 Global Land Surface Altimetry Data, version 34, NASA National Snow and Ice Data Center Distributed Active Archive Center, Boulder, Colorado, USA, https://doi.org/10.5067/ICESAT/GLAS/DATA227, 2009. 